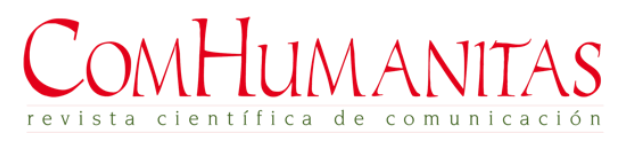

Revista ComHumanitas, ISSN: 1390-776X

Vol. 11, núm. 3 (2020), Septiembre - Diciembre 2020

DOI: https://doi.org/10.31207/rch.v11i3.272

\title{
Estrategias utilizadas por los influencers ecuatorianos como agentes del marketing digital, para promover la venta de productos y servicios en la red social Instagram
}

Strategies used by ecuadorian influencers as agents of digital marketing, to promote the sale of products and services in the social network Instagram

Estratégias usadas pelos influencers equatorianos como agentes de marketing digital para promover a venda de produtos e serviços na rede social do Instagram

\author{
Sonia Lizzette Rivera Abad ${ }^{1}$ \\ Universidad de Los Hemisferios (Ecuador) \\ sonirivera7@gmail.com
}

Fecha de recepción: 10 de diciembre de 2020

Fecha de recepción evaluador: 13 de diciembre de 2020

Fecha de recepción corrección: 20 de diciembre de 2020

\footnotetext{
${ }^{1}$ Sonia Lizzette Rivera Abad: Magister en Investigación de Comunicación Digital, por la Universidad de los Hemisferios, Sede Ecuador. Licenciada en Comunicación con énfasis en Comunicación Audiovisual y Guión, por la Universidad de los Hemisferios. Fotógrafa y Realizadora Audiovisual. Actualmente desempeña el cargo de Asistente de Comunicación Social en el Ministerio de Transporte y Obras Públicas de la ciudad de Quito, Ecuador. ORCID: https://orcid.org/0000-0002-3463-3397
} 


\title{
Resumen
}

Esta investigación analiza las estrategias utilizadas por influencers del medio ecuatoriano en la red social Instagram y da a conocer las principales marcas que apuestan por el marketing digital para promocionar sus productos y servicios con el público joven. La investigación expone la creatividad y los recursos utilizados por los influencers que buscan demostrar a sus seguidores que lleva un estilo de vida saludable, atractivo y en tendencia. La metodología que emplea este estudio se basa en el modelo de "Netnología" propuesta por Miguel del Fresno, el cual combina la recolección de datos (número de publicaciones, número de seguidores y número de usuarios seguidos) con manifestaciones gráficas tales como fotos, videos e historias de Instagram. También se utiliza el método de entrevistas de tipo personal y virtual, donde los influencers aportan una mayor aproximación de su trabajo. La información recolectada se muestra a través de tablas y análisis comparativos, revelando la estrategia que los influencers utilizan para promocionar a las marcas.

Palabras Clave: Estrategia digital, influencers, marketing digital, marketing de influencia, redes sociales, Instagram.

\begin{abstract}
This research analyzes the strategies used by Ecuadorian influencers in the Instagram social network and announces the main brands that are committed to digital marketing to promote their products and services with the young public. The research exposes the creativity and resources used by influencers who seek to demonstrate to their followers that they lead a healthy, attractive and trending lifestyle. The methodology used in this study is based on the "Netnology" model proposed by Miguel del Fresno, which combines data collection (number of publications, number of followers and number of users followed) with graphic manifestations such as photos, videos and Instagram stories. The method of personal and virtual interviews is also used, where influencers provide a greater approximation of their work. The information collected is shown through tables and comparative analysis, revealing the strategy that influencers use to promote brands.
\end{abstract}

Keywords: Digital strategy, influencers, digital marketing, influence marketing, social networks, Instagram.

\section{Resumo}

Esta pesquisa analisa as estratégias utilizadas pelos influencers no meio equatoriano na rede social Instagram e revela as principais marcas comprometidas com o marketing digital para promover seus produtos e serviços com o público jovem. A pesquisa expõe a criatividade e os recursos utilizados pelos influencers que procuram demonstrar aos seus seguidores que eles levam um estilo de vida saudável, atraente e de tendência. A metodologia utilizada neste estudo é baseada no modelo "Netnologia" proposto por Miguel del Fresno, que combina a coleta de dados (número de publicações, número de seguidores e número de usuários seguidos) com manifestações gráficas, como fotos, 
vídeos e histórias do Instagram. Também é utilizado o método de entrevistas pessoais e virtuais, onde os influencers fornecem uma maior aproximação ao seu trabalho. As informações coletadas são mostradas em tabelas e análises comparativas, revelando a estratégia que os influencers usam para promover às marcas.

Palavras-chave: Estratégia digital, influencers, marketing digital, marketing de influência, redes sociais, Instagram.

\section{Introducción}

El influencer es una persona que cuenta con una alta credibilidad en redes sociales y que puede llegar a convertirse en un fuerte embajador de marca. Existe una diferencia abismal entre la publicidad tradicional (prensa, radio y televisión) y el marketing digital que utiliza el alcance online para llegar a un público objetivo concreto. Según la agencia de publicidad Nabraivi: "En Ecuador existen más de 10 millones de usuarios en Facebook y unos 2,6 millones en Instagram" (Cisneros, 2018). Y es precisamente esta última red social, el escenario perfecto para la promoción de distintos productos y servicios.

El fenómeno influencer comenzó en 2011 de la mano de grandes firmas como Starbucks o Nike, que optaron por pagar a celebridades del medio local, para que comiencen a subir fotos de sus productos junto con una pequeña reseña positiva. "En el caso de la cadena estadounidense Starbucks, esta comenzó a regalar café a todos quienes suban una foto mostrando el característico envase de café con un hashtag o etiqueta referente a la popular cadena de cafeterías" (Angulo, 2017).

Esta investigación busca definir por qué las marcas se han alejado de los medios tradicionales para optar por este modelo publicitario. En el medio ecuatoriano, existen marcas internacionales como Adidas que a manera de canje o mediante pago en efectivo han seleccionado a personas jóvenes con un estilo de vida aparente, para que utilicen sus productos y compartan una publicación positiva de dicha marca en redes sociales. De ahí nace la siguiente pregunta de investigación: ¿Cuáles son las estrategias que utilizan los influencers ecuatorianos para promover la venta de productos y servicios en la red social Instagram?

Para responder a esta pregunta, la investigación hace un análisis de las cuentas de los 20 influencers ecuatorianos con mayor número de seguidores en Instagram, donde el proceso de observación es clave para determinar cuáles son las publicaciones y manifestaciones gráficas como fotos, videos e historias de mayor relevancia que presenten un alto nivel de producción y creatividad, con el objetivo de identificar cuáles son las estrategias que utilizan los influencers ecuatorianos para promover la venta de productos y servicios en la red social Instagram. 


\section{Marco Referencial}

\section{El marketing digital}

Los influencers son los personajes idóneos para mostrar una imagen de juventud, tecnología y estilo de vida sano, demostrando que son íconos de la moda y de las nuevas tendencias en cada una de sus publicaciones. Y es precisamente la industria de la moda, la que más invierte en herramientas de marketing digital. "Las marcas de moda han aprovechado la capacidad de los influencers de recomendar cuáles serán las tendencias de temporada, consiguiendo así que sus colecciones sean vistas por miles de seguidores en distintos canales. A menudo, estas figuras también reciben prendas y accesorios de las marcas" (Curiel-Pérez \& Luque, 2017, p. 275).

Los expertos en marketing digital han sabido aprovechar los recursos tecnológicos para llegar de manera más dinámica e interactiva a sus potenciales clientes. Como explica Henry Jenkins, en su libro Blogueros y Videojuegos. La cultura de la colaboración: "Las tendencias económicas que favorecen los conglomerados mediáticos horizontalmente integrados fomentan el flujo de imágenes, ideas y narraciones a través de múltiples canales mediáticos y demandan tipos más activos de espectadores" (Jenkins, 2009, p. 163).

Antes de optar por este modelo de negocio, las empresas tuvieron que realizar un cauteloso estudio de mercado, donde pudieron determinar a qué edades corresponde su principal grupo objetivo, si son hombres, mujeres, qué tipo de lugares frecuentan y sobretodo, qué marcas o productos se encuentran dentro de sus compras habituales y cuánto dinero están dispuestos a utilizar. Dicho estudio debería estar basado en una amplia compilación de cifras estadísticas dentro de la demografía de una ciudad o país. $\mathrm{Al}$ respecto, Nicholas Negroponte afirma lo siguiente:

Se asume que la individualización es la extrapolación de la transmisión selectiva. En el momento en que tienen nuestra dirección, estado civil, edad, ingresos, marca del coche, compras, hábitos de bebida e impuestos, ya nos han cazado: somos una unidad demográfica de una persona. (Negroponte, 1995, p. 13)

Y es que, debido a la información personal que se publica en redes sociales, las marcas tienen en la mira a sus potenciales clientes. Pero, ¿por qué recurren a los influencers? Si una adolescente de 17 años ve una publicación en su Instagram de su actor favorito visitando una famosa cafetería de la ciudad, es probable que no sólo le de like a la publicación, sino que también etiquete a sus amigas y se pongan de acuerdo para visitarla. En el caso de los medios masivos, el mensaje llega de forma general a la población, mientras que gracias a los influencers el mensaje llegó mejor focalizado.

La identificación de grupos sociales es vital para determinar a qué grupo objetivo se quiere llegar, para vender de mejor manera el producto. Sin embargo, "todos los científicos sociales concuerdan en que los grupos tienen que ser creados y recreados nuevamente por otros medios no sociales, y que nunca existe un agrupamiento que pueda sostener su existencia sin algún mantenimiento" (Latour, 2008, p. 60). Ciertamente, esto 
es algo que se irá renovando continuamente y los grupos no van a ser siempre los mismos, ya que cada día surgirán nuevas tendencias o movimientos en redes sociales, de usuarios con necesidades diferentes a las que tenían un año atrás.

\section{El marketing de Influencia}

El impacto de los influencers ha sido tan positivo a nivel mundial que las marcas, además de pautar en medios tradicionales (prensa, radio y televisión), destinan una parte de sus recursos para vincular la marca a jóvenes voceros que promocionen sus productos en redes sociales. Tal como lo explica Shayne Bowman, en su libro Nosotros el medio: "La economía de la red y la proliferación de medios presentan un desafío tremendo para las organizaciones de medios tradicionales, tales como los periódicos, la radio y la televisión" (Bowman \& Willis, 2003, p. 20). La sociedad se encuentra ante la inminente ruptura de los medios de comunicación tradicionales, en donde las redes sociales y las distintas aplicaciones para celular facilitan hoy en día la difusión de contenidos y la promoción de productos y servicios.

Es por esto, que los medios tradicionales están cada vez más en la obligación de crear contenido dirigido a este grupo objetivo de jóvenes ávidos de información que ven en las calles o en internet, publicidad, fotos y contenido audiovisual. Actualmente, se vive una cultura de la instantaneidad y de lo reemplazable, nada logra mantenerse por mucho tiempo ni ganarse nuestra aceptación por siempre. Tal como lo explica Zygmunt Bauman: "Lo mismo ocurre en una cultura de consumo como la nuestra, partidaria de los productos listos para uso inmediato, las soluciones rápidas, la satisfacción instantánea, y los resultados que no requieran esfuerzos prolongados" (Bauman, 2003, p. 15).

En definitiva, los influencers han sabido aprovechar todos estos vacíos generacionales, mostrando una realidad alterna en redes sociales. Y obviamente, las marcas han sabido obtener ventaja de esto a través del marketing de influencia. Si un influencer demuestra que un determinado producto es bueno, aunque no lo sea, llenará un vacío emocional en otra persona y le dará una razón para comprarlo. La autora Estefanía Guerrero afirma lo siguiente:

El $81 \%$ de los profesionales del marketing y comunicación consideran las relaciones con influencers muy eficaces. De hecho, la utilización de influencers en campañas de marketing incrementa el recuerdo, el reconocimiento y el valor de la marca, además de crear oportunidades comerciales e incrementar la posibilidad de compra. (Guerrero, 2017, p. 11)

El fenómeno influencer se ha vuelto tan popular que según el propio Henry Jenkins, en su libro Cultura Transmedia: "A menudo profesionales de las relaciones públicas han utilizado el lenguaje del influenciador para justificar la importancia de ir más allá de los periodistas y alcanzar a los blogueros" (Jenkins, 2013, p. 99). Si bien Jenkins afirma que en el mundo publicitario se está recurriendo a los influencers por encima de los medios tradicionales, también demuestra que no son indispensables. Según una investigación en el 2003: 
Se puso a prueba esta hipótesis pidiendo a 60.000 personas que se pusieran en contacto con 18 personas en 13 países reenviando un e-mail a algún amigo o conocido. Se encontró que los núcleos o personas muy conectadas no fueron vitales en este proceso, ya que solo un 5\% pasó a través de ellos" (Jenkins, 2013, p. 99).

Aunque se pueda prescindir de los influencers es cierto que cada vez más las empresas apuestan por trabajar con ellos. Incluso se leen publicaciones en Facebook de negocios locales buscando reclutar nuevos influencers, donde piden como requisito enviar nombre de usuario en Instagram, número de seguidores, y un video explicando por qué serían buenos embajadores de la marca. Una vez avanzada la negociación se llega a un acuerdo formal y se presenta al cliente un media kit con el detalle de costo por publicación. También, se puede observar a los propios influencers promocionando una marca determinada, sin recibir nada a cambio, con la finalidad de que la marca se interese en ellos.

Para asegurar el éxito de una relación marca-influencer es necesario tomar en cuenta varios factores. En primer lugar, es necesario escoger a la persona que represente e identifique a la marca, gracias a su personalidad, estilo de vida, edad y hábitos de consumo. "La marca debe analizar bien al influenciador puesto que no todos encajan con los valores y objetivos de una marca. Por eso hay que investigar muy bien cuáles son sus capacidades y aptitudes y adaptarlos de forma que la marca se pueda beneficiar de ellas" (Rubio, 2017, p. 33).

El influencer debe convertirse en un embajador de la marca, que comparta con sus seguidores fotografías y videos, utilizando el producto de la marca que representa. Pero que se note que forma parte de su estilo de vida y no lo haga solo por cumplir con un número determinado de publicaciones. El público no es ingenuo y también puede pasar lo contrario de lo que se quería lograr, y el influencer escogido termine expresando una imagen negativa de la marca.

Cada vez es más común que los usuarios se remitan a la configuración de su privacidad y ajustes, en donde pueden desactivar la opción de publicidad no deseada. Pero con los influencers pasa algo diferente, ya que su visualización es consentida por el usuario. Según Begoña Gómez:

El influencer de marketing, no se ve afectado por el bloqueo al ser un contenido no intrusivo que demanda el usuario. La publicidad mediante los influencers puede infringir el principio de identificación, sin embargo, resulta mucho más creíble una opinión ofrecida por un influencer que por la propia marca. (Gómez, 2018, p. 7)

Si bien el impacto es alto, es recomendable no utilizar esta modalidad si no va acorde a los valores corporativos de la empresa, aunque en la mayoría de los casos los efectos sean positivos. Como explica Denise Brown: "Bajo una planificación adecuada y como complemento a otras herramientas del marketing puede suponer un aumento en el crecimiento de la marca y mejoramiento de la relación con su público objetivo en redes sociales" (Brown, 2016, p. 59). 
En definitiva "Un influencer es un líder de opinión que rompe con la jerarquía y verticalidad tradicional porque la comunicación entre dos partes es simultánea, empleando contenidos cuya base sea la emoción y empatía para que así el mensaje sea interpretado de forma directa dentro de un entorno confiable y creíble" (García, 2017, p. 26). Ciertamente, tanto el usuario como el influencer, comparten edades, gustos y estilos de vida similares, y es por esta misma razón que les resulta tan fácil crear un vínculo de credibilidad y confianza.

En conclusión, el marketing de influencia es altamente efectivo, por la manera en que se comunica y llega al público objetivo deseado. A su vez, los usuarios les otorgan el poder de convencimiento necesario a celebridades del mundo virtual para ayudar a las grandes marcas a determinar nuestros hábitos de consumo. Las fotografías expuestas también manifiestan la vanidad y el narcisismo oculto de muchas personas que encontraron en las redes sociales, el espacio ideal para desarrollarse.

\section{Estrategias digitales en el mercado ecuatoriano}

Según el Instituto Ecuatoriano de Estadística y Censos (INEC): "En Ecuador existen 17,3 millones de habitantes, de los cuales el 14,7 millones tienen acceso a Internet y 12 millones son usuarios de redes sociales" (INEC, 2018). Aunque el uso de redes sociales con fines personales es bastante significativo, en Ecuador existen jóvenes emprendedores que basan su estrategia en plataformas digitales como Facebook e Instagram para anunciar sus productos, y sin disponer de un local físico, consiguen captar la atención de sus potenciales clientes. Sin embargo, todavía no existe mucha bibliografía al respecto.

En el caso de Facebook, sigue siendo la red social más popular entre los usuarios ecuatorianos y el primer lugar donde se crea una fanpage para promocionar un negocio. Según el autor Oscar López: "Las empresas luchan por tener contenidos nuevos, historias que enganchen e incorporen múltiples contenidos visuales y gráficos al comunicarse. Facebook ha sido un excelente espacio para experimentar recurriendo a una rápida innovación con el fin de lograr una mejor forma de contar historias a sus fans" (Oscar López, 2018, p. 11).

En Facebook se pueden encontrar páginas de artistas, negocios grandes y emprendimientos pequeños. Además, existe la posibilidad de descargar una aplicación llamada Administrador de páginas, que permite el acceso a mensajes, métricas, nivel de crecimiento de la página, número de impresiones e interacciones. Incluso, sugiere al administrador cuando es el mejor momento para subir contenido, la frecuencia, y presenta un detalle completo del nivel de alcance de cada publicación.

Gran parte de las empresas ecuatorianas continúan aplicando su estrategia en Facebook, sin embargo, es Instagram la red social con mejor y mayor aceptación hacia el público joven. La estrategia de los pequeños emprendedores consiste en crear alianzas con marcas que dispongan de puntos de venta físicos, para que los ayuden a promocionar 
sus productos a través de redes sociales. Lo que buscan es apalancarse de marcas ya posicionadas y con un gran número de seguidores para vender más fácilmente.

Por otro lado, algunas marcas optan por lanzar concursos o los denominados giveaways para incrementar rápidamente sus seguidores, y dar a conocer sus productos. Por lo general, la persona responsable de armar la estrategia es el community manager $(C M)$, quien es el profesional de marketing digital encargado de gestionar la comunidad online de una marca o empresa. Esta persona trabaja de la mano con el diseñador gráfico para plasmar las publicaciones según las directrices del área comercial. Sin embargo, existen dueños de marcas que prefieren realizar este proceso ellos mismos y de forma empírica.

Según el Instituto Ecuatoriano de Estadística y Censos: "El 72,2\% de la población nacional cuenta con un teléfono inteligente" (INEC, 2018), por lo que una buena parte de los ecuatorianos están propensos a recibir publicidad en sus smartphones. El alcance online de las redes sociales es impresionante, pero pese a que es una gran oportunidad, todavía existen empresas que desconocen todo su potencial. Tal como plantea Oscar López a continuación:

El Marketing Digital por medio de redes sociales, es un campo poco desarrollado en las Pymes del Ecuador. El motivo principal parece ser la falta de conocimiento, el miedo a cambiar del marketing tradicional al Marketing Digital; así como el desconocimiento de la inversión frente a medios tradicionales. Este hecho constituye una oportunidad para que las Pymes inviertan en Marketing Digital, específicamente aprovechando el potencial de las redes sociales, que en la actualidad están bien posicionadas. (Oscar López, 2018, p. 14)

En definitiva, son muy pocas las empresas ecuatorianas que poseen una estrategia digital consolidada y es por esto, que existen empresas dedicadas al asesoramiento online y manejo de marca en redes sociales. Sin embargo, las empresas que sí manejan herramientas de marketing digital poseen una ventaja competitiva impresionante frente a las demás marcas del mercado. Adicionalmente, se puede integrar los servicios de los influencers para dar a conocer un negocio, dependiendo del público objetivo que se quiera llegar.

\section{Promoción de productos y servicios en Instagram}

En la actualidad, Instagram permite múltiples posibilidades para potenciar un negocio al máximo. Facilita la opción de crear páginas para empresas, donde se puede evidenciar índices de reputación, tráfico y penetración de la marca. "Las empresas de estudios de mercado o redes sociales como Facebook e Instagram permiten reflejar estadísticas de forma exacta y directa, permitiendo crear y mantener una base de datos de clientes. De esta forma el canal de comunicación es controlado como un canal de distribución" (Castagnino, 2017, p. 21).

Instagram ofrece una ventaja superior frente a las demás plataformas y es que, su contenido se caracteriza por ser $90 \%$ visual, lleno de fotografías, videos, boomerangs e historias, donde el usuario simplemente con deslizar el dedo hacia abajo para enterarse 
de la actividad de las cuentas que sigue. Se trata de público joven en su mayoría que busca acceder a contenido visual llamativo sin tener que leer extensas líneas de texto. Por su parte, las marcas buscan ser cada vez más creativas en la manera de presentar sus productos, mediante fotos, animaciones o a través de la herramienta Instagram Shop, la cual direcciona automáticamente a la página de $e$-commerce de la empresa.

Importantes firmas como Gucci, no solo usan esta red para promocionar, de manera directa, sus productos, sino que, ahora, se comparten imágenes de desfiles, del backstage, de la selección de tejidos y de temas que antes eran secretos y exclusivos de la empresa. Es una técnica más visual, informal y rápida para establecer una comunicación entre la firma y sus seguidores/as. (Curiel-Pérez \& Sanz, 2019, p. 12)

Cuando un influencer acepta convertirse en vocero de una marca, por lo general recibe regalos por parte de su cliente (ropa, zapatos, comida o consumos en establecimientos). Para esto, el influencer debe estar comprometido con los valores de la marca y su estilo de vida debe ir acorde a lo que la misma representa. Además, debe cumplir con un determinado número de publicaciones diario. Si el cliente o en este caso la marca, evidencia un crecimiento significativo en sus ventas, no sólo renovará el contrato por prestación de servicios, sino que, además, buscará tener la exclusividad de su embajador de marca, negándole la posibilidad de trabajar para marcas de la competencia.

Por delante de la eficacia del influencer existen factores relacionados con la interacción directa marca-consumidor/a, en modo offline y online. En el caso de una empresa como Gucci, la bidireccionalidad, el engagement y sobre todo el conocimiento de la cultura, los gustos y la opinión de un público objetivo millennial, constituyen una serie de estrategias que explican un cambio que no solo afecta a los modos de comunicación, sino que influye también en los modos de producción. (Curiel-Pérez \& Sanz, 2019, p. 8)

El tipo de promoción dependerá del producto o servicio que se quiera vender. En el caso del maquillaje, las influencers mujeres suben una serie de tutoriales de cómo maquillarse correctamente haciendo siempre mención a la marca, o incluso pueden organizar una clase magistral con demostraciones en vivo, regalos, concursos para transmitirlos en directo vía Instagram, con el fin de captar nuevas clientas y fidelizar a las ya existentes.

En el caso de los alimentos, muchos influencers optan por demostrar sus habilidades culinarias para agregar una serie de historias, desde la obtención del producto, su preparación, resultado final y la degustación del mismo. En cambio, para los deportistas, la ropa o el suplemento nutricional que promocionan, pasa a ser parte de su rutina diaria de entrenamiento, por lo que bastará con compartir una foto y una historia mientras realizan alguna actividad física. 


\section{Metodología}

\section{Observación virtual}

La metodología seleccionada para esta investigación se fundamenta en el modelo de "Netnología" propuesta por Miguel del Fresno, basada en la observación en redes sociales, es de tipo no experimental y longitudinal. Ya que la investigación parte de un momento determinado, en este caso desde junio de 2018 hasta febrero de 2019, siendo el tiempo de nueve meses exactamente. La muestra escogida es de tipo no probabilística y seleccionando a los 20 influencers con mayor número de seguidores en Ecuador. Hombres y mujeres de edades entre 15 a 40 años de las ciudades de Quito y Guayaquil.

\section{Recopilación y clasificación de datos}

La investigación es de enfoque mixto. En primer lugar, de tipo cuantitativa, mediante la elaboración de tablas para clasificar a los influencers por nombre de su cuenta de Instagram, número de publicaciones, número de seguidores y número de personas seguidas. Para luego, identificar cuáles son las marcas o empresas que promocionan sus productos y servicios mediante influencers en la red social Instagram. Dividiéndolas en tres categorías: a) Moda y Belleza; b) Productos gastronómicos y c) Tecnología y servicios. Finalmente, la investigación presenta un cuadro comparativo sobre las herramientas digitales utilizadas, tipos de interacciones y estructura temporal en Instagram.

\section{Entrevistas}

En segundo lugar, la parte cualitativa está basada en fuentes primarias de personas y hechos concretos. En este caso, se escogió a 4 influencers que forman parte de la muestra escogida para que concedan una entrevista de 10 preguntas vía WhatsApp. Se contará con el testimonio de la influencer y maquillista profesional Andrea Navarrete, quien basa su estrategia en realizar tutoriales de maquillaje y consejos de cuidado personal. También está la presentadora y modelo Karol Noboa, quien comprende el marketing de influencia como un negocio y saca provecho de su imagen muy bien consolidada en el medio ecuatoriano, para promocionar diversas marcas.

Por otro lado, el guayaquileño Jesse Gallardo, quien se caracteriza por crear contenido original en Instagram y por ser un referente de la moda juvenil en Ecuador. Y por último el actor y realizador Jorge Ulloa quien se dio a conocer internacionalmente gracias a su canal de YouTube: EnchufeTv y quien actualmente es imagen de marcas que proyectan un alto estatus social.

Se utilizará la técnica de observación personal-directa a los influencers de Quito a través de un mapeo en redes sociales durante los nueve meses propuestos en esta investigación. Según el modelo de "Netnología" planteada por Miguel del Fresno: "La descripción participante o la descripción no participante son viables en el contexto social online. Se reduce a una decisión de método, ya que el investigador puede participar de 
forma abierta o permanecer como observador no participante mientras sea metodológicamente oportuno para la investigación" (Del Fresno, 2011, p. 82)

\section{Hallazgos}

\section{Recopilación y clasificación de datos}

Los 20 influencers ecuatorianos con mayor número de seguidores en Instagram, fueron clasificados en tres grandes grupos: a) Famosos de pantalla: Flor María Palomeque, Carolina Jaume, Michela Pincay, Erika Vélez, María Teresa Guerrero, Constanza Báez, Gaby Díaz, Carolina Aguirre, Karol Noboa y Ale Boada; b) YouTubers: Jorge Ulloa, Carolina Flor, Jota Arias y Richard Salazar; c) Influencers no famosos: Cristina Maag, Samara Montero, Andrea Navarrete, Jesse Gallardo, Fabrizio Zambrano y Lavinia Valbonesi.

Los siguientes cuadros comparativos, están comprendidos de junio de 2018 a febrero de 2019, momento en que se realizó la etapa de observación. Se expone la popularidad de los influencers ecuatorianos en orden descendente. Cabe aclarar que los famosos de pantalla alcanzaron cifras más altas, debido a su aparición en televisión y programas de farándula, mientras que los denominados YouTubers, se dieron a conocer por subir contenido viral a sus canales de YouTube y por último los influencers no famosos, que son personas normales que gracias a su llamativo estilo de vida, captaron la atención de las marcas, a esto le sumamos factores como creatividad y constancia en sus publicaciones.

Tabla 1.

\begin{tabular}{|c|c|c|c|c|c|}
\hline & $\begin{array}{l}\text { NOMBRE } \\
\text { INFLUENCER }\end{array}$ & CUENTA EN & $\begin{array}{c}\text { NÚMERO DE } \\
\text { PUBLICACIONES }\end{array}$ & $\begin{array}{l}\text { NÚMERO DE } \\
\text { SEGUIDORES }\end{array}$ & $\begin{array}{l}\text { NÚMERO } \\
\text { DE } \\
\text { SEGUIDO } \\
\text { S }\end{array}$ \\
\hline 1 & $\begin{array}{l}\text { Flor María } \\
\text { Palomeque }\end{array}$ & @flor_mpalomeque & 8.848 & 1,4 millones & 654 \\
\hline 2 & Carolina Jaume & @ carolinajaume & 7.667 & 1,2 millones & 1.597 \\
\hline 3 & Michela Pincay & @ michelapinbu & 5.760 & 1 millón & 1.990 \\
\hline 4 & Erika Vélez & @erikavelez & 3.389 & 1 millón & 699 \\
\hline 5 & $\begin{array}{l}\text { María Teresa } \\
\text { Guerrero }\end{array}$ & @ flacaguerrerog & 8.397 & $942 \mathrm{mil}$ & 2.687 \\
\hline 6 & $\begin{array}{l}\text { Constanza } \\
\text { Báez }\end{array}$ & @ constanzabaezjalil & 2.814 & 519 mil & 1.191 \\
\hline 7 & Gaby Díaz & @gabydiazaragon & 8.332 & $338 \mathrm{mil}$ & 2.088 \\
\hline 8 & Jorge Ulloa & @jorgeulloaaa & 565 & $265 \mathrm{mil}$ & 419 \\
\hline 9 & Cristina Maag & $@$ frontrow.ec & 2.211 & 205 mil & 5.903 \\
\hline
\end{tabular}




\begin{tabular}{|c|c|c|c|c|c|}
\hline $\begin{array}{l}1 \\
0\end{array}$ & $\begin{array}{l}\text { Samara } \\
\text { Montero }\end{array}$ & @ samara_montero & 923 & 153 mil & 748 \\
\hline $\begin{array}{l}1 \\
1\end{array}$ & Jota Arias & @iamjotarias & 1.166 & $150 \mathrm{mil}$ & 575 \\
\hline $\begin{array}{l}1 \\
2\end{array}$ & $\begin{array}{c}\text { Andrea } \\
\text { Navarrete }\end{array}$ & @andreanmakeup & 4.137 & 109 mil & 3.683 \\
\hline 1 & Karol Noboa & @karolnoboa & 2.694 & 103 mil & 837 \\
\hline $\begin{array}{l}1 \\
4\end{array}$ & $\begin{array}{l}\text { Carolina } \\
\text { Aguirre }\end{array}$ & @ caroaguirreperez & 1.616 & $100 \mathrm{mil}$ & 1.855 \\
\hline 1 & Carolina Flor & @ carolinapflor & 744 & 92,7 mil & 440 \\
\hline 1 & Ale Boada & @ale_boada & 1.499 & 66,6 mil & 599 \\
\hline 1 & Jesse Gallardo & @jessegallardom & 346 & 66,2 mil & 740 \\
\hline $\begin{array}{l}1 \\
8\end{array}$ & $\begin{array}{l}\text { Richard } \\
\text { Salazar }\end{array}$ & $\begin{array}{c}@ \text { richardsalazarbaron } \\
\text { a }\end{array}$ & 375 & $59,2 \mathrm{mil}$ & 255 \\
\hline $\begin{array}{l}1 \\
9\end{array}$ & $\begin{array}{l}\text { Fabrizio } \\
\text { Zambrano }\end{array}$ & @fzzioza & 1.613 & $54,1 \mathrm{mil}$ & 911 \\
\hline $\begin{array}{l}2 \\
0\end{array}$ & $\begin{array}{l}\text { Lavinia } \\
\text { Valbonesi }\end{array}$ & @laviniavalbonesi_ & 1.297 & 50,4 mil & 980 \\
\hline
\end{tabular}

Fuente: Instagram junio de 2018 - Elaboración propia

Tabla 2.

\begin{tabular}{|c|c|c|c|c|c|}
\hline & $\begin{array}{l}\text { NOMBRE } \\
\text { INFLUENCE } \\
\text { R }\end{array}$ & CUENTA EN & $\begin{array}{c}\text { NÚMERO DE } \\
\text { PUBLICACIONE } \\
\text { S }\end{array}$ & $\begin{array}{c}\text { NÚMERO DE } \\
\text { SEGUIDORE } \\
\text { S }\end{array}$ & $\begin{array}{l}\text { NÚMERO } \\
\text { DE } \\
\text { SEGUIDO } \\
\text { S }\end{array}$ \\
\hline 1 & $\begin{array}{l}\text { Flor María } \\
\text { Palomeque }\end{array}$ & @flor_mpalomeque & 8.960 & 1,5 millones & 661 \\
\hline 2 & $\begin{array}{l}\text { Carolina } \\
\text { Jaume }\end{array}$ & @carolinajaume & 7.736 & 1,2 millones & 1.617 \\
\hline 3 & $\begin{array}{l}\text { Michela } \\
\text { Pincay }\end{array}$ & @michelapinbu & 5.793 & 1 millón & 2.001 \\
\hline 4 & Erika Vélez & @erikavelez & 3.410 & 1 millón & 694 \\
\hline 5 & $\begin{array}{c}\text { María Teresa } \\
\text { Guerrero }\end{array}$ & @flacaguerrerog & 8.477 & 960 mil & 2.767 \\
\hline 6 & $\begin{array}{l}\text { Constanza } \\
\text { Báez }\end{array}$ & @constanzabaezjalil & 2.821 & 519 mil & 1.208 \\
\hline 7 & Gaby Díaz & @gabydiazaragon & 8.416 & 347 mil & 2.118 \\
\hline
\end{tabular}




\begin{tabular}{|c|c|c|c|c|c|}
\hline 8 & Jorge Ulloa & @jorgeulloaaa & 568 & $268 \mathrm{mil}$ & 439 \\
\hline 9 & Cristina Maag & @ frontrow.ec & 2.253 & 205 mil & 5.713 \\
\hline $\begin{array}{l}1 \\
0\end{array}$ & $\begin{array}{l}\text { Samara } \\
\text { Montero }\end{array}$ & @ samara_montero & 928 & $161 \mathrm{mil}$ & 783 \\
\hline $\begin{array}{l}1 \\
1\end{array}$ & Jota Arias & @iamjotarias & 1.193 & $150 \mathrm{mil}$ & 586 \\
\hline $\begin{array}{l}1 \\
2\end{array}$ & $\begin{array}{c}\text { Andrea } \\
\text { Navarrete }\end{array}$ & @andreanmakeup & 4.186 & $112 \mathrm{mil}$ & 3.846 \\
\hline $\begin{array}{l}1 \\
3\end{array}$ & Karol Noboa & @karolnoboa & 2.716 & $100 \mathrm{mil}$ & 856 \\
\hline $\begin{array}{l}1 \\
4\end{array}$ & $\begin{array}{l}\text { Carolina } \\
\text { Aguirre }\end{array}$ & @ caroaguirreperez & 1.635 & $105 \mathrm{mil}$ & 1.862 \\
\hline $\begin{array}{l}1 \\
5\end{array}$ & Carolina Flor & @ carolinapflor & 751 & 94,7 mil & 444 \\
\hline $\begin{array}{l}1 \\
6\end{array}$ & Ale Boada & @ale_boada & 1.542 & 68,2 mil & 598 \\
\hline $\begin{array}{l}1 \\
7\end{array}$ & Jesse Gallardo & @jessegallardom & 354 & $67,3 \mathrm{mil}$ & 740 \\
\hline $\begin{array}{l}1 \\
8\end{array}$ & $\begin{array}{l}\text { Richard } \\
\text { Salazar }\end{array}$ & @ richardsalazarbarona & 385 & $62,2 \mathrm{mil}$ & 268 \\
\hline $\begin{array}{l}1 \\
9\end{array}$ & $\begin{array}{c}\text { Fabrizio } \\
\text { Zambrano }\end{array}$ & @fzzioza & 1.637 & 52,4 mil & 918 \\
\hline $\begin{array}{l}2 \\
0\end{array}$ & $\begin{array}{c}\text { Lavinia } \\
\text { Valbonesi }\end{array}$ & @laviniavalbonesi_ & 1.324 & $58,5 \mathrm{mil}$ & 987 \\
\hline
\end{tabular}

Fuente: Instagram julio de 2018 - Elaboración propia

Tabla 3.

\begin{tabular}{|c|c|c|c|c|c|}
\hline & $\begin{array}{l}\text { NOMBRE } \\
\text { INFLUENCER }\end{array}$ & $\begin{array}{l}\text { CUENTA EN } \\
\text { INSTAGRAM }\end{array}$ & $\begin{array}{c}\text { NÚMERO DE } \\
\text { PUBLICACIONES }\end{array}$ & $\begin{array}{l}\text { NÚMERO DE } \\
\text { SEGUIDORES }\end{array}$ & $\begin{array}{l}\text { NÚMERO } \\
\text { DE } \\
\text { SEGUIDO } \\
\text { S }\end{array}$ \\
\hline 1 & $\begin{array}{l}\text { Flor María } \\
\text { Palomeque }\end{array}$ & @flor_mpalomeque & 9.082 & 1,5 millones & 667 \\
\hline 2 & Carolina Jaume & @carolinajaume & 7.779 & 1,3 millones & 1.633 \\
\hline 3 & Michela Pincay & @michelapinbu & 5.820 & 1 millón & 1.973 \\
\hline 4 & Erika Vélez & @erikavelez & 3.416 & 1 millón & 700 \\
\hline 5 & $\begin{array}{c}\text { María Teresa } \\
\text { Guerrero }\end{array}$ & @flacaguerrerog & 8.527 & 970 mil & 2.815 \\
\hline 6 & $\begin{array}{c}\text { Constanza } \\
\text { Báez }\end{array}$ & @constanzabaezjalil & 2.843 & $521 \mathrm{mil}$ & 1.232 \\
\hline
\end{tabular}




\begin{tabular}{|c|c|c|c|c|c|}
\hline 7 & Gaby Díaz & @gabydiazaragon & 8.489 & $352 \mathrm{mil}$ & 2.174 \\
\hline 8 & Jorge Ulloa & @jorgeulloaaa & 577 & $275 \mathrm{mil}$ & 430 \\
\hline 9 & Cristina Maag & @ frontrow.ec & 2.280 & 208 mil & 5.815 \\
\hline $\begin{array}{l}1 \\
0\end{array}$ & $\begin{array}{l}\text { Samara } \\
\text { Montero }\end{array}$ & @ samara_montero & 940 & $177 \mathrm{mil}$ & 812 \\
\hline $\begin{array}{l}1 \\
1\end{array}$ & Jota Arias & @iamjotarias & 1.200 & $151 \mathrm{mil}$ & 588 \\
\hline $\begin{array}{l}1 \\
2\end{array}$ & $\begin{array}{c}\text { Andrea } \\
\text { Navarrete }\end{array}$ & @andreanmakeup & 4.221 & $117 \mathrm{mil}$ & 3.595 \\
\hline $\begin{array}{l}1 \\
3\end{array}$ & Karol Noboa & @karolnoboa & 2.747 & $101 \mathrm{mil}$ & 854 \\
\hline $\begin{array}{l}1 \\
4\end{array}$ & $\begin{array}{l}\text { Carolina } \\
\text { Aguirre }\end{array}$ & @ caroaguirreperez & 1.672 & $108 \mathrm{mil}$ & 1.885 \\
\hline $\begin{array}{l}1 \\
5\end{array}$ & Carolina Flor & @ carolinapflor & 756 & 96 mil & 449 \\
\hline $\begin{array}{l}1 \\
6\end{array}$ & Ale Boada & @ale_boada & 1.570 & $70,1 \mathrm{mil}$ & 596 \\
\hline $\begin{array}{l}1 \\
7\end{array}$ & Jesse Gallardo & @jessegallardom & 362 & $69 \mathrm{mil}$ & 741 \\
\hline $\begin{array}{l}1 \\
8\end{array}$ & $\begin{array}{l}\text { Richard } \\
\text { Salazar }\end{array}$ & $\begin{array}{c}\text { @ richardsalazarbaron } \\
\text { a }\end{array}$ & 388 & 64,4 mil & 278 \\
\hline $\begin{array}{l}1 \\
9\end{array}$ & $\begin{array}{l}\text { Fabrizio } \\
\text { Zambrano }\end{array}$ & @fzzioza & 1.655 & $50,9 \mathrm{mil}$ & 950 \\
\hline $\begin{array}{l}2 \\
0\end{array}$ & $\begin{array}{c}\text { Lavinia } \\
\text { Valbonesi }\end{array}$ & @laviniavalbonesi_ & 1.355 & $65,5 \mathrm{mil}$ & 980 \\
\hline
\end{tabular}

Fuente: Instagram agosto de 2018 - Elaboración propia

Tabla 4.

\section{NOMBRE INFLUENCE $\mathrm{R}$}

CUENTA EN

INSTAGRAM

$1 \quad$ Flor María

Palomeque

2 Carolina Jaume

$3 \quad$ Michela Pincay

4 Erika Vélez

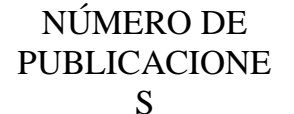

$\mathrm{S}$

9.151

7.841

5.851

3.433
NÚMERO DE SEGUIDORE $\mathrm{S}$

NÚMERO

DE SEGUIDO $\mathrm{S}$

665

1,5 millones

1,3 millones

1.646

1 millón

1.989

1,1 millón

705 


\begin{tabular}{|c|c|c|c|c|c|}
\hline 5 & $\begin{array}{c}\text { María Teresa } \\
\text { Guerrero }\end{array}$ & @ flacaguerrerog & 8.609 & 982 mil & 2.865 \\
\hline 6 & $\begin{array}{l}\text { Constanza } \\
\text { Báez }\end{array}$ & @constanzabaezjalil & 2.849 & $526 \mathrm{mil}$ & 1.240 \\
\hline 7 & Gaby Díaz & @gabydiazaragon & 8.560 & 357 mil & 2.206 \\
\hline 8 & Jorge Ulloa & @jorgeulloaaa & 582 & 282 mil & 446 \\
\hline 9 & Cristina Maag & @ frontrow.ec & 2.325 & $201 \mathrm{mil}$ & 5.514 \\
\hline 10 & $\begin{array}{c}\text { Samara } \\
\text { Montero }\end{array}$ & @ samara_montero & 977 & 199 mil & 788 \\
\hline 11 & Jota Arias & @iamjotarias & 1.220 & $151 \mathrm{mil}$ & 589 \\
\hline 12 & $\begin{array}{c}\text { Andrea } \\
\text { Navarrete }\end{array}$ & @andreanmakeup & 4.271 & $121 \mathrm{mil}$ & 926 \\
\hline 13 & Karol Noboa & $@$ karolnoboa & 2.760 & $101 \mathrm{mil}$ & 874 \\
\hline 14 & $\begin{array}{l}\text { Carolina } \\
\text { Aguirre }\end{array}$ & @ caroaguirreperez & 1.700 & $110 \mathrm{mil}$ & 1.887 \\
\hline 15 & Carolina Flor & @ carolinapflor & 745 & 96,8 mil & 454 \\
\hline 16 & Ale Boada & @ale_boada & 1.605 & 72,7 mil & 595 \\
\hline 17 & Jesse Gallardo & @ jessegallardom & 367 & 69,6 mil & 757 \\
\hline 18 & $\begin{array}{l}\text { Richard } \\
\text { Salazar }\end{array}$ & @ richardsalazarbarona & 363 & 64,2 mil & 271 \\
\hline 19 & $\begin{array}{c}\text { Fabrizio } \\
\text { Zambrano }\end{array}$ & @ fzzioza & 1.663 & 49,8 mil & 1.040 \\
\hline 20 & $\begin{array}{c}\text { Lavinia } \\
\text { Valbonesi }\end{array}$ & @laviniavalbonesi_ & 1.414 & 62,5 mil & 1.017 \\
\hline
\end{tabular}

Fuente: Instagram septiembre de 2018 - Elaboración propia

Tabla 5.

\begin{tabular}{|c|c|c|c|c|c|}
\hline & NOMBRE & CUENTA EN & NÚMERO DE & NÚMERO DE & NÚMERO \\
\hline & INFLUENCE & & PUBLICACIONE & SEGUIDORE & DE \\
\hline & $\mathrm{R}$ & INSTAGRAM & $\mathrm{S}$ & $\mathrm{S}$ & $\begin{array}{c}\text { SEGUIDO } \\
\mathrm{S}\end{array}$ \\
\hline 1 & $\begin{array}{l}\text { Flor María } \\
\text { Palomeque }\end{array}$ & @ flor_mpalomeque & 9.194 & 1,5 millones & 668 \\
\hline 2 & $\begin{array}{l}\text { Carolina } \\
\text { Jaume }\end{array}$ & @carolinajaume & 7.863 & 1,3 millones & 1.655 \\
\hline 3 & Erika Vélez & @erikavelez & 3.440 & 1,1 millón & 705 \\
\hline 4 & $\begin{array}{l}\text { Michela } \\
\text { Pincay }\end{array}$ & @ michelapinbu & 5.860 & 1 millón & 1.987 \\
\hline
\end{tabular}




\begin{tabular}{|c|c|c|c|c|c|}
\hline 5 & $\begin{array}{c}\text { María Teresa } \\
\text { Guerrero }\end{array}$ & @flacaguerrerog & 8.632 & 986 mil & 2.880 \\
\hline 6 & $\begin{array}{l}\text { Constanza } \\
\text { Báez }\end{array}$ & @ constanzabaezjalil & 2.852 & 526 mil & 1.245 \\
\hline 7 & Gaby Díaz & @gabydiazaragon & 8.597 & 359 mil & 2.207 \\
\hline 8 & Jorge Ulloa & @jorgeulloaaa & 588 & $287 \mathrm{mil}$ & 456 \\
\hline 9 & Cristina Maag & @ frontrow.ec & 2.343 & 202 mil & 5.399 \\
\hline 10 & $\begin{array}{l}\text { Samara } \\
\text { Montero }\end{array}$ & @ samara_montero & 992 & 204 mil & 794 \\
\hline 11 & Jota Arias & @iamjotarias & 1.244 & $151 \mathrm{mil}$ & 588 \\
\hline 12 & $\begin{array}{c}\text { Andrea } \\
\text { Navarrete }\end{array}$ & @andreanmakeup & 4.290 & $121 \mathrm{mil}$ & 929 \\
\hline 13 & Karol Noboa & @karolnoboa & 2.773 & $101 \mathrm{mil}$ & 880 \\
\hline 14 & $\begin{array}{c}\text { Carolina } \\
\text { Aguirre }\end{array}$ & @ caroaguirreperez & 1.711 & $111 \mathrm{mil}$ & 1.889 \\
\hline 15 & Carolina Flor & @ carolinapflor & 750 & $97,1 \mathrm{mil}$ & 458 \\
\hline 16 & Ale Boada & @ale_boada & 1.615 & 73,5 mil & 596 \\
\hline 17 & Jesse Gallardo & @jessegallardom & 370 & $69,5 \mathrm{mil}$ & 753 \\
\hline 18 & $\begin{array}{l}\text { Richard } \\
\text { Salazar }\end{array}$ & @ richardsalazarbarona & 369 & 64,4 mil & 270 \\
\hline 19 & $\begin{array}{c}\text { Lavinia } \\
\text { Valbonesi }\end{array}$ & @laviniavalbonesi_ & 1.424 & $62,3 \mathrm{mil}$ & 1.021 \\
\hline 20 & $\begin{array}{l}\text { Fabrizio } \\
\text { Zambrano }\end{array}$ & $@$ @zzioza & 1.668 & 49,6 mil & 1.007 \\
\hline
\end{tabular}

Fuente: Instagram octubre 2018 - Elaboración propia

Tabla 6.

\begin{tabular}{|c|c|c|c|c|c|}
\hline & NOMBRE & CUENTA EN & NÚMERO DE & NÚMERO DE & NÚMERO \\
\hline & $\begin{array}{c}\text { INFLUENCE } \\
\text { R }\end{array}$ & INSTAGRAM & $\begin{array}{c}\text { PUBLICACIONE } \\
\text { S }\end{array}$ & $\begin{array}{l}\text { SEGUIDORE } \\
\mathrm{S}\end{array}$ & $\begin{array}{c}\text { DE } \\
\text { SEGUIDO } \\
\mathrm{S}\end{array}$ \\
\hline 1 & $\begin{array}{l}\text { Flor María } \\
\text { Palomeque }\end{array}$ & @flor_mpalomeque & 9.281 & 1,6 millones & 658 \\
\hline 2 & $\begin{array}{l}\text { Carolina } \\
\text { Jaume }\end{array}$ & @carolinajaume & 7.902 & 1,3 millones & 1.694 \\
\hline 3 & Erika Vélez & @erikavelez & 3.420 & 1,1 millón & 698 \\
\hline 4 & $\begin{array}{l}\text { Michela } \\
\text { Pincay }\end{array}$ & @ michelapinbu & 5.886 & 1,1 millón & 2.029 \\
\hline
\end{tabular}




\begin{tabular}{|c|c|c|c|c|c|}
\hline 5 & $\begin{array}{c}\text { María Teresa } \\
\text { Guerrero }\end{array}$ & @flacaguerrerog & 8.727 & 1 millón & 2.962 \\
\hline 6 & $\begin{array}{l}\text { Constanza } \\
\text { Báez }\end{array}$ & @ constanzabaezjalil & 2.872 & $530 \mathrm{mil}$ & 1.259 \\
\hline 7 & Gaby Díaz & @gabydiazaragon & 8.699 & $368 \mathrm{mil}$ & 2.242 \\
\hline 8 & Jorge Ulloa & @jorgeulloaaa & 594 & 292 mil & 477 \\
\hline 9 & Cristina Maag & @ frontrow.ec & 2.412 & 203 mil & 5.797 \\
\hline 10 & $\begin{array}{l}\text { Samara } \\
\text { Montero }\end{array}$ & @ samara_montero & 1.014 & $230 \mathrm{mil}$ & 685 \\
\hline 11 & Jota Arias & @iamjotarias & 1.281 & $151 \mathrm{mil}$ & 594 \\
\hline 12 & $\begin{array}{c}\text { Andrea } \\
\text { Navarrete }\end{array}$ & @andreanmakeup & 4.333 & $122 \mathrm{mil}$ & 937 \\
\hline 13 & Karol Noboa & @karolnoboa & 2.815 & 104 mil & 898 \\
\hline 14 & $\begin{array}{c}\text { Carolina } \\
\text { Aguirre }\end{array}$ & @ caroaguirreperez & 1.735 & 113 mil & 1.904 \\
\hline 15 & Carolina Flor & @ carolinapflor & 758 & $98,1 \mathrm{mil}$ & 506 \\
\hline 16 & Ale Boada & @ale_boada & 1.643 & $76,5 \mathrm{mil}$ & 604 \\
\hline 17 & Jesse Gallardo & @jessegallardom & 373 & $70,5 \mathrm{mil}$ & 744 \\
\hline 18 & $\begin{array}{l}\text { Richard } \\
\text { Salazar }\end{array}$ & @ richardsalazarbarona & 372 & 64,3 mil & 271 \\
\hline 19 & $\begin{array}{c}\text { Lavinia } \\
\text { Valbonesi }\end{array}$ & @laviniavalbonesi_ & 1.502 & 73,7 mil & 1.046 \\
\hline 20 & $\begin{array}{l}\text { Fabrizio } \\
\text { Zambrano }\end{array}$ & $@$ @zzioza & 1.673 & $48,8 \mathrm{mil}$ & 1.017 \\
\hline
\end{tabular}

Fuente: Instagram noviembre 2018 - Elaboración propia

Tabla 7.

\begin{tabular}{|c|c|c|c|c|c|}
\hline & $\begin{array}{c}\text { NOMBRE } \\
\text { INFLUENCE } \\
\mathrm{R}\end{array}$ & CUENTA EN & $\begin{array}{c}\text { NÚMERO DE } \\
\text { PUBLICACIONE } \\
\text { S }\end{array}$ & $\begin{array}{c}\text { NÚMERO DE } \\
\text { SEGUIDORE } \\
\text { S }\end{array}$ & $\begin{array}{l}\text { NÚMERO } \\
\text { DE } \\
\text { SEGUIDO } \\
\text { S }\end{array}$ \\
\hline 1 & $\begin{array}{l}\text { Flor María } \\
\text { Palomeque }\end{array}$ & @ flor_mpalomeque & 9.327 & 1,6 millones & 656 \\
\hline 2 & $\begin{array}{c}\text { Carolina } \\
\text { Jaume }\end{array}$ & @carolinajaume & 7.923 & 1,4 millones & 1.702 \\
\hline 3 & Erika Vélez & @erikavelez & 3.415 & 1,1 millón & 710 \\
\hline 4 & $\begin{array}{l}\text { Michela } \\
\text { Pincay }\end{array}$ & $@$ michelapinbu & 5.856 & 1,1 millón & 2.067 \\
\hline
\end{tabular}




\begin{tabular}{|c|c|c|c|c|c|}
\hline 5 & $\begin{array}{c}\text { María Teresa } \\
\text { Guerrero }\end{array}$ & @flacaguerrerog & 8.775 & 1 millón & 2.934 \\
\hline 6 & $\begin{array}{l}\text { Constanza } \\
\text { Báez }\end{array}$ & @ constanzabaezjalil & 2.881 & 544 mil & 1.288 \\
\hline 7 & Gaby Díaz & @gabydiazaragon & 8.674 & $371 \mathrm{mil}$ & 2.287 \\
\hline 8 & Jorge Ulloa & @jorgeulloaaa & 603 & $300 \mathrm{mil}$ & 500 \\
\hline 9 & Cristina Maag & @ frontrow.ec & 2.461 & $203 \mathrm{mil}$ & 5.812 \\
\hline 10 & $\begin{array}{l}\text { Samara } \\
\text { Montero }\end{array}$ & @ samara_montero & 1.030 & 248 mil & 708 \\
\hline 11 & Jota Arias & @iamjotarias & 1.299 & $153 \mathrm{mil}$ & 591 \\
\hline 12 & $\begin{array}{c}\text { Andrea } \\
\text { Navarrete }\end{array}$ & @andreanmakeup & 4.359 & $123 \mathrm{mil}$ & 944 \\
\hline 13 & Karol Noboa & @karolnoboa & 2.859 & 106 mil & 905 \\
\hline 14 & $\begin{array}{c}\text { Carolina } \\
\text { Aguirre }\end{array}$ & @ caroaguirreperez & 1.747 & $115 \mathrm{mil}$ & 1.907 \\
\hline 15 & Carolina Flor & @ carolinapflor & 762 & 98,7 mil & 534 \\
\hline 16 & Ale Boada & @ale_boada & 1.658 & 77,8 mil & 612 \\
\hline 17 & Jesse Gallardo & @jessegallardom & 377 & $71 \mathrm{mil}$ & 718 \\
\hline 18 & $\begin{array}{l}\text { Richard } \\
\text { Salazar }\end{array}$ & @ richardsalazarbarona & 380 & 64,3 mil & 268 \\
\hline 19 & $\begin{array}{c}\text { Lavinia } \\
\text { Valbonesi }\end{array}$ & @laviniavalbonesi_ & 1.544 & 91,4 mil & 1.064 \\
\hline 20 & $\begin{array}{l}\text { Fabrizio } \\
\text { Zambrano }\end{array}$ & $@$ @zzioza & 1.683 & 48,4 mil & 1.023 \\
\hline
\end{tabular}

Fuente: Instagram diciembre 2018 - Elaboración propia

Tabla 8.

\begin{tabular}{|c|c|c|c|c|c|}
\hline & NOMBRE & CUENTA EN & NÚMERO DE & NÚMERO DE & NÚMERO \\
\hline & $\begin{array}{c}\text { INFLUENCE } \\
\text { R }\end{array}$ & INSTAGRAM & $\begin{array}{c}\text { PUBLICACIONE } \\
\text { S }\end{array}$ & $\begin{array}{l}\text { SEGUIDORE } \\
\mathrm{S}\end{array}$ & $\begin{array}{c}\text { DE } \\
\text { SEGUIDO } \\
\mathrm{S}\end{array}$ \\
\hline 1 & $\begin{array}{l}\text { Flor María } \\
\text { Palomeque }\end{array}$ & @flor_mpalomeque & 9.400 & 1,6 millones & 660 \\
\hline 2 & $\begin{array}{l}\text { Carolina } \\
\text { Jaume }\end{array}$ & @carolinajaume & 7.932 & 1,4 millones & 1.600 \\
\hline 3 & Erika Vélez & @erikavelez & 3.400 & 1,1 millón & 706 \\
\hline 4 & $\begin{array}{l}\text { Michela } \\
\text { Pincay }\end{array}$ & @ michelapinbu & 5.850 & 1,1 millón & 2.095 \\
\hline
\end{tabular}




\begin{tabular}{|c|c|c|c|c|c|}
\hline 5 & $\begin{array}{c}\text { María Teresa } \\
\text { Guerrero }\end{array}$ & @flacaguerrerog & 8.815 & 1 millón & 3.561 \\
\hline 6 & $\begin{array}{l}\text { Constanza } \\
\text { Báez }\end{array}$ & @ constanzabaezjalil & 2.900 & 548 mil & 1.232 \\
\hline 7 & Gaby Díaz & @gabydiazaragon & 8.726 & $380 \mathrm{mil}$ & 2.300 \\
\hline 8 & Jorge Ulloa & @jorgeulloaaa & 607 & $310 \mathrm{mil}$ & 515 \\
\hline 9 & Cristina Maag & @ frontrow.ec & 2.502 & 203 mil & 5.562 \\
\hline 10 & $\begin{array}{l}\text { Samara } \\
\text { Montero }\end{array}$ & @ samara_montero & 1.065 & $300 \mathrm{mil}$ & 731 \\
\hline 11 & Jota Arias & @iamjotarias & 1.323 & $160 \mathrm{mil}$ & 595 \\
\hline 12 & $\begin{array}{c}\text { Andrea } \\
\text { Navarrete }\end{array}$ & @andreanmakeup & 4.390 & $123,6 \mathrm{mil}$ & 966 \\
\hline 13 & Karol Noboa & @karolnoboa & 2.878 & 107 mil & 913 \\
\hline 14 & $\begin{array}{c}\text { Carolina } \\
\text { Aguirre }\end{array}$ & @ caroaguirreperez & 1.740 & 120 mil & 1.920 \\
\hline 15 & Carolina Flor & @ carolinapflor & 769 & 99 mil & 610 \\
\hline 16 & Ale Boada & @ale_boada & 1.688 & 79,9 mil & 633 \\
\hline 17 & Jesse Gallardo & @jessegallardom & 379 & $71,2 \mathrm{mil}$ & 711 \\
\hline 18 & $\begin{array}{l}\text { Richard } \\
\text { Salazar }\end{array}$ & @ richardsalazarbarona & 385 & 65 mil & 288 \\
\hline 19 & $\begin{array}{c}\text { Lavinia } \\
\text { Valbonesi }\end{array}$ & @laviniavalbonesi_ & 1.590 & $92,1 \mathrm{mil}$ & 1.091 \\
\hline 20 & $\begin{array}{c}\text { Fabrizio } \\
\text { Zambrano }\end{array}$ & $@$ @zzioza & 1.695 & 47 mil & 1.047 \\
\hline
\end{tabular}

Fuente: Instagram enero 2019 - Elaboración propia

Tabla 9.

\begin{tabular}{|c|c|c|c|c|c|}
\hline & $\begin{array}{c}\text { NOMBRE } \\
\text { INFLUENCE } \\
\text { R }\end{array}$ & CUENTA EN & $\begin{array}{c}\text { NÚMERO DE } \\
\text { PUBLICACIONE } \\
\text { S }\end{array}$ & $\begin{array}{c}\text { NÚMERO DE } \\
\text { SEGUIDORE } \\
\text { S }\end{array}$ & $\begin{array}{l}\text { NÚMERO } \\
\text { DE } \\
\text { SEGUIDO } \\
\text { S }\end{array}$ \\
\hline 1 & $\begin{array}{l}\text { Flor María } \\
\text { Palomeque }\end{array}$ & @ flor_mpalomeque & 9.435 & 1,6 millones & 666 \\
\hline 2 & $\begin{array}{c}\text { Carolina } \\
\text { Jaume }\end{array}$ & @carolinajaume & 7.942 & 1,4 millones & 1.586 \\
\hline 3 & Erika Vélez & @erikavelez & 3.393 & 1,2 millón & 701 \\
\hline 4 & $\begin{array}{l}\text { Michela } \\
\text { Pincay }\end{array}$ & $@$ michelapinbu & 5.844 & 1,1 millón & 2.127 \\
\hline
\end{tabular}




\begin{tabular}{|c|c|c|c|c|c|}
\hline 5 & $\begin{array}{c}\text { María Teresa } \\
\text { Guerrero }\end{array}$ & @flacaguerrerog & 8.897 & 1 millón & 3.025 \\
\hline 6 & $\begin{array}{l}\text { Constanza } \\
\text { Báez }\end{array}$ & @ constanzabaezjalil & 2.908 & $552 \mathrm{mil}$ & 1.222 \\
\hline 7 & Gaby Díaz & @gabydiazaragon & 8.779 & 388 mil & 2.356 \\
\hline 8 & Jorge Ulloa & @jorgeulloaaa & 611 & $313 \mathrm{mil}$ & 528 \\
\hline 9 & Cristina Maag & @ frontrow.ec & 2.535 & 202 mil & 5.250 \\
\hline 10 & $\begin{array}{l}\text { Samara } \\
\text { Montero }\end{array}$ & @ samara_montero & 1.073 & 319 mil & 753 \\
\hline 11 & Jota Arias & @iamjotarias & 1.340 & 164 mil & 601 \\
\hline 12 & $\begin{array}{c}\text { Andrea } \\
\text { Navarrete }\end{array}$ & @andreanmakeup & 4.408 & 124 mil & 973 \\
\hline 13 & Karol Noboa & @karolnoboa & 2.900 & 108 mil & 925 \\
\hline 14 & $\begin{array}{c}\text { Carolina } \\
\text { Aguirre }\end{array}$ & @ caroaguirreperez & 1.738 & $126 \mathrm{mil}$ & 1.930 \\
\hline 15 & Carolina Flor & @ carolinapflor & 773 & 99,2 mil & 601 \\
\hline 16 & Ale Boada & @ale_boada & 1.709 & $81,8 \mathrm{mil}$ & 633 \\
\hline 17 & Jesse Gallardo & @jessegallardom & 383 & $71,7 \mathrm{mil}$ & 700 \\
\hline 18 & $\begin{array}{l}\text { Richard } \\
\text { Salazar }\end{array}$ & @ richardsalazarbarona & 390 & 67,9 mil & 294 \\
\hline 19 & $\begin{array}{c}\text { Lavinia } \\
\text { Valbonesi }\end{array}$ & @laviniavalbonesi_ & 1.605 & 93,7 mil & 1.114 \\
\hline 20 & $\begin{array}{l}\text { Fabrizio } \\
\text { Zambrano }\end{array}$ & @fzzioza & 1.709 & $47,1 \mathrm{mil}$ & 1.066 \\
\hline
\end{tabular}

Fuente: Instagram febrero 2019 - Elaboración propia

En el caso de Flor María Palomeque, es la influencer que ha registrado un mayor incremento en sus seguidores de 1,4 millones a 1,6 millones (junio de 2018 febrero de 2019). Pero este crecimiento es subjetivo, ya que lleva una ventaja considerable gracias a su larga trayectoria profesional en medios televisivos. También, se registró un descenso de seguidores en la cuenta de Cristina Maag de 203 mil a 202 mil seguidores de enero a febrero de 2019. Probablemente, se debió a que ella depuró varias de las cuentas a las que seguía en ese mismo mes. Otro punto a considerar, es que la cuenta de Jesse Gallardo fue eliminada debido a un hackeo que sufrió una vez terminado el periodo de observación, por lo que tuvo que crearse una nueva cuenta con un número de seguidores mucho menor al que tenía antes.

\section{Categorización}

Durante el periodo de observación, la investigación determinó que las marcas mencionadas a continuación, escogieron el marketing de influencia como estrategia para 
potenciar sus ventas en Instagram. Las marcas fueron divididas en tres grandes categorías: a) Moda y Belleza: Adidas, De Prati, Eta Fashion, Las Fragancias, L'Occitane, Millani Ecuador, Mush, MAC cosméticos, Yanbal, Bio Femme, Óptica Los Andes (OLA), Hot Shapers, Íntima Ecuador, Tiffany\&Co, Tommy Hilfiger, Watch World Ecuador, Nike, Old Spice, Nutribela 10, Flormar Ecuador, entre otros.

En la categoría Gastronomía: Frutaris, Magnum, Granuts, galletas Saníssimo, Pepsi Ecuador, Colcafé, Pizza Hut Ecuador, McDonald's Ecuador, Stevia Life, 7UP Ecuador, azúcar Valdez, Real Ecuador, Braun, Cocoa La Universal, Yummi Ecuador, Bimbo, Pilsener Light, Promise PE GOLD, Quesos la Holandesa, Güitig, Johnnie Walker, entre otros.

Y en la categoría de Tecnología y Servicios: Tuenti, Be Produbanco, BG Magazine, Domicilios.com, Odontocenter, Amazing Tour, Smartfit Ecuador, Cabify Ecuador, Toyota Ecuador, Selina, Bluefon Mobile, HP Ecuador, Banco del Austro, Claro Ecuador, Samsung Latinoamérica, Radio FM mundo, Sony Mobile, HT Fitness Center, SmartSim, EF Ecuador, entre otros.

Tabla 10.

\begin{tabular}{|c|c|c|c|}
\hline \multirow{10}{*}{ CATEGORÍAS } & \multirow[t]{2}{*}{ MODA Y BELLEZA } & GASTRONOMÍA Y & TECNOLOGÍA Y \\
\hline & & PRODUCTOS & SERVICIOS \\
\hline & Adidas & Frutaris & Tuenti \\
\hline & De Prati & Magnum & Be Produbanco \\
\hline & Las Fragancias & Quesos la Holandesa & BG Magazine \\
\hline & L'Occitane & Galletas Saníssimo & Domicilios.com \\
\hline & Millani Ecuador & Pepsi Ecuador & Odontocenter \\
\hline & Mush & Pizza Hut Ecuador & Amazing Tour \\
\hline & Óptica Los Andes & McDonald's Ecuador & Samsung \\
\hline & (OLA) & & Latinoamérica \\
\hline MARCA O & MAC cosméticos & Stevia Life & Smartfit Ecuador \\
\hline \multirow[t]{4}{*}{ EMPRESA } & Hot Shapers & 7UP Ecuador & Cabify Ecuador \\
\hline & Watch World Ecuador & Promise & Claro \\
\hline & & PE GOLD & Ecuador \\
\hline & Tiffany\&Co & Azúcar Valdez & Toyota Ecuador \\
\hline
\end{tabular}




$\begin{array}{ccc}\text { Yanbal } & \text { Yummi Ecuador } & \text { Selina } \\ \text { Bio Femme } & \text { Bimbo } & \text { Bluefon Mobile } \\ \text { Tommy Hilfiger } & \text { Pilsener Light } & \text { SmartSim } \\ \text { Nike } & \text { Braun } & \text { EF Ecuador } \\ \text { Old Spice } & \text { Cocoa La Universal } & \text { HT Fitness Center } \\ \text { Nutribela 10 } & \text { Real Ecuador } & \text { Banco del Austro } \\ \text { Eta Fashion } & \text { Colcafé } & \text { Sony Mobile } \\ \text { Íntima Ecuador } & \text { Güitig } & \text { HP Ecuador } \\ \text { Flormar Ecuador } & \text { Johnnie Walker } & \text { Radio FM mundo }\end{array}$

Fuente: Instagram junio de 2018 - Elaboración propia

\section{Distribución}

Como parte de su estrategia digital, en el siguiente cuadro comparativo se encuentran las marcas que han utilizado la imagen de un influencer como embajador de marca o para una campaña determinada. Según el segmento al que quieren llegar, marcas como Pampers y Promise PE GOLD pautan con reconocidas madres de la televisión ecuatoriana como: Flor María Palomeque y Gaby Díaz. Mientras que las marcas que desean llegar a un público más joven como Magnum o McDonald’s Ecuador, pautan con influencers como: Samara Montero y Cristina Maag, cuyas publicaciones consisten en demostrar un estilo de vida mucho más llamativo.

Tabla 11.

NOMBRE
INFLUENCER

1

$$
\begin{aligned}
& \text { Flor María } \\
& \text { Palomeque }
\end{aligned}
$$

2 Carolina Jaume

3 Michela Pincay
CUENTA EN INSTAGRAM

@flor_mpalomeque

@ carolinajaume

@ michelapinbu

\section{MARCA O EMPRESA}

Promise PE GOLD

Cocoa La Universal

Hot Shapers

Domicilios.com

Amazing Tour

HT Fitness Center

SmartSim

Tuenti

Íntima Ecuador 


\begin{tabular}{|c|c|c|c|}
\hline & & & Yummi Ecuador \\
\hline \multirow[t]{4}{*}{4} & Erika Vélez & @erikavelez & Millani Ecuador \\
\hline & & & SmartSim \\
\hline & & & Claro Ecuador \\
\hline & & & Real Ecuador \\
\hline \multirow[t]{4}{*}{5} & María Teresa & @flacaguerrerog & Hot Shapers \\
\hline & & & Nutribela 10 \\
\hline & & & Banco del Austro \\
\hline & & & Eta Fashion \\
\hline \multirow[t]{3}{*}{6} & Constanza Báez & @ constanzabaezjalil & Pepsi Ecuador \\
\hline & & & Claro Ecuador \\
\hline & & & Magnum \\
\hline \multirow[t]{3}{*}{7} & Gaby Díaz & @gabydiazaragon & Eta Fashion \\
\hline & & & Colcafé \\
\hline & & & Sony Mobile \\
\hline \multirow[t]{2}{*}{8} & Jorge Ulloa & @ jorgeulloaaa & Old Spice \\
\hline & & & Be Produbanco \\
\hline \multirow[t]{8}{*}{9} & Cristina Maag & $@$ frontrow.ec & Tiffany\&Co \\
\hline & & & L'Occitane \\
\hline & & & Magnum \\
\hline & & & Stevia Life \\
\hline & & & SmartSim \\
\hline & & & MAC cosméticos \\
\hline & & & Watch World Ecuador \\
\hline & & & Óptica Los Andes (OLA) \\
\hline \multirow[t]{6}{*}{10} & Samara Montero & @ samara_montero & McDonald's Ecuador \\
\hline & & & Pizza Hut Ecuador \\
\hline & & & Tommy Hilfiger \\
\hline & & & EF Ecuador \\
\hline & & & 7UP Ecuador \\
\hline & & & Güitig \\
\hline 11 & Jota Arias & $@$ iamjotarias & Magnum \\
\hline
\end{tabular}


SmartSim

Tommy Hilfiger

Johnnie Walker

Galletas Saníssimo

Watch World Ecuador

@andreanmakeup

De Prati

Mush

MAC cosméticos

Bio Femme

Flormar Ecuador

13 Karol Noboa

@karolnoboa

Óptica Los Andes (OLA)

Galletas Saníssimo

Toyota Ecuador

Stevia Life

HP Ecuador

Radio FM mundo

14 Carolina Aguirre

@ caroaguirreperez

Nike

Yanbal

15 Carolina Flor

@ carolinapflor

Be Produbanco

Galletas Saníssimo

16

Ale Boada

@ale_boada

Smartfit Ecuador

Odontocenter

Cabify Ecuador

Pilsener Light

17 Jesse Gallardo

@jessegallardom

Adidas

Braun

De Prati

Tuenti

Stevia Life

BG Magazine

Galletas Saníssimo

Be Produbanco 
Be Produbanco

Frutaris

@fzzioza

Galletas Saníssimo

Azúcar Valdez

Selina

Bluefon Mobile

Samsung Latinoamérica

20 Lavinia Valbonesi

@laviniavalbonesi_

Bimbo

Stevia Life

Bio Femme

Galletas Saníssimo

Quesos la Holandesa

Fuente: Instagram junio de 2018 - Elaboración propia

\section{Tipos de interacciones en Instagram}

En el siguiente cuadro comparativo, se aprecian las interacciones que disponen los usuarios de la red social Instagram, donde predomina el uso de filtros de fotografía y video, la utilización de historias como medio para comunicar una actividad, suceso o concurso y el uso de emojis, gifs, likes y comentarios como forma de interacción entre usuarios. También, se constató el uso de la herramienta IGTV para subir videos de $10 \mathrm{o}$ hasta 60 minutos en el caso de cuentas oficiales o que cuenten con una alta popularidad. 
Tabla 12.

ACCIONES

HERRAMIENTAS
DIGITALES

Instagram permite la utilización de aplicaciones y filtros de fotografía como:

- Filtros de Instagram

- VSCO

- Airbrush

- Pic collage

Para subir videos e historias las herramientas más populares son los siguientes:

- Filtros de Instagram

- Boomerang

- Superzoom

- Rewind

- Tik Tok
TIPOS DE INTERACCIONES
Los tipos de interacciones más populares en Instagram son los siguientes:

- Hashtags

- Menciones

- Mensajes directos

- Me gusta (like)

- Comentarios

- Emojis

- Stickers

También son muy populares los concursos Giveaway, en donde los usuarios tienen la oportunidad de ganarse premios de marcas de diseñador o consumos en restaurantes, solo con dar like a la publicación, comentar y etiquetar a otros amigos para tener más oportunidades de ganar.

Instagram permite la posibilidad de hacer preguntas o encuestas en sus historias, gracias a un termómetro que indica si la
IMAGEN
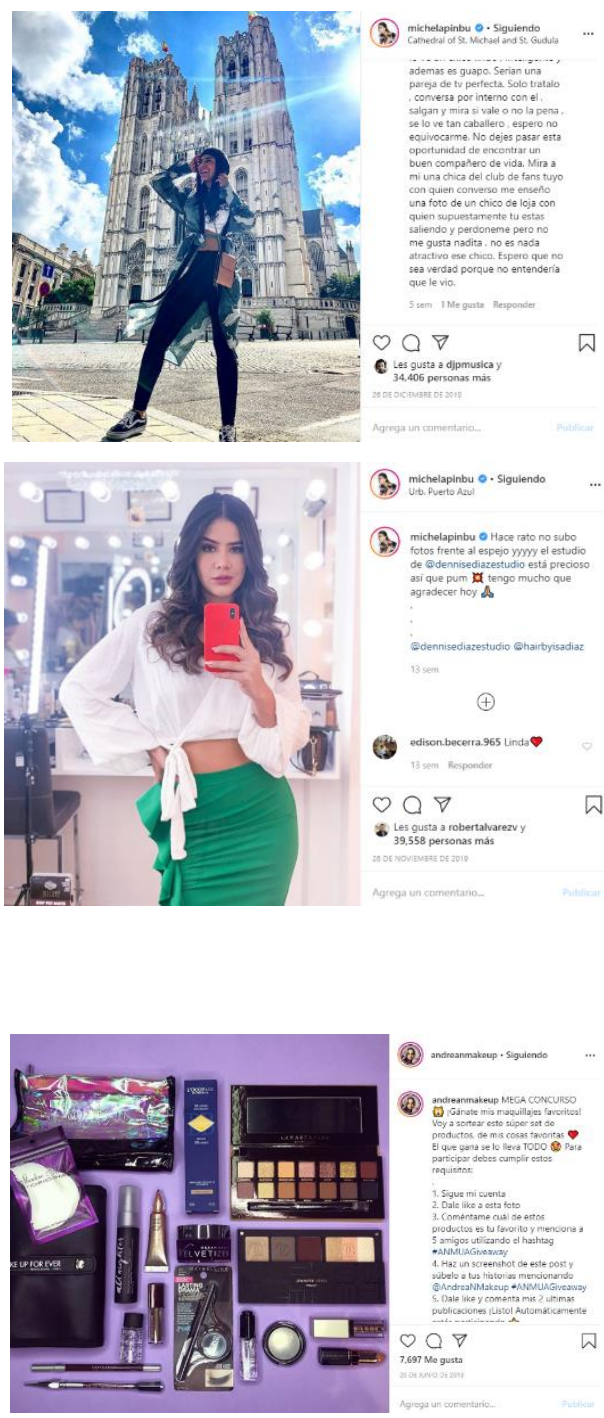
pregunta gusta o no. Esto le permite al usuario recibir retroalimentación por parte de sus seguidores.
ESTRUCTURA TEMPORAL
Es de tipo sincrónica y da la posibilidad a sus usuarios de ver transmisiones en vivo, donde las personas pueden interactuar y comentar en tiempo real. Por su parte, la herramienta IGTV permite a los usuarios cargar videos verticales de 10 minutos o hasta 60 minutos en el caso de cuentas oficiales.
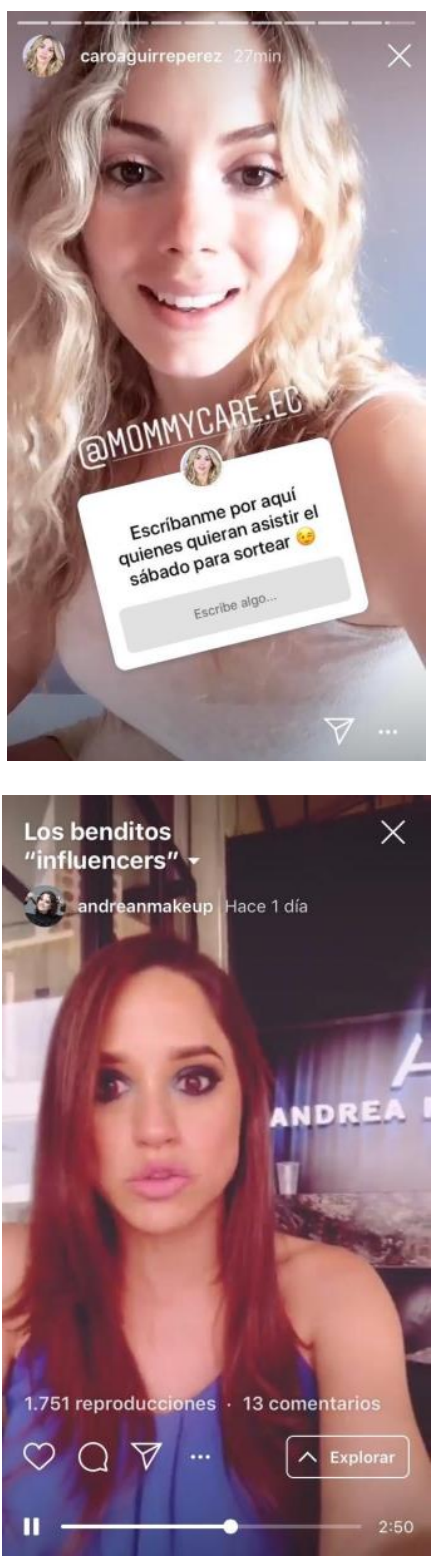

Fuente: Elaboración propia

\section{Entrevistas}

Según la influencer y maquillista Andrea Navarrete, las marcas deben tener una filosofía o fondo de ayuda, que la distinga del resto por su compromiso social o ambiental y que no sea otra marca simplemente dedicada a vender productos. Andrea sostiene que la marca debe estar alineada a los valores propios de sus influencers. En su caso, ella comparte mucho el concepto de L'Occitane que vende salud, naturalidad y productos sin químicos nocivos para la salud. Y ella precisamente, trabaja con este tipo de materiales durante sus clases maestras o mientras graba tutoriales, porque comparte la misma filosofía de la marca y el resultado es mucho más natural.

Para la modelo y locutora de radio Karol Noboa, ser influencer implica una gran responsabilidad, ya que se influye en la toma de decisión del cliente y esto puede repercutir positivamente en las ventas de una marca. Las marcas compran el estilo de 
vida, la imagen y el nicho de mercado de sus embajadores de marca. Cada influencer tiene un concepto, patrones que no se pueden romper y colores que se deben respetar. Es por esto, que las marcas se adaptan a su influencer y no al contrario.

Jesse Gallardo por su parte, sostiene que no necesariamente, un número elevado de seguidores lo convierte en influencer. Existen personas que se hicieron famosas gracias a sus apariciones en prensa y televisión, y personas que tienen pocos seguidores en Instagram, pero que llegan a un nicho muy específico de seguidores orgánicos. En el caso de un nutricionista, la gente lo sigue por su contenido y es capaz de influir directamente sobre su público, ya que el mensaje llega mucho más claro y directo.

Por otro lado, Jorge Ulloa se ha ganado el cariño y aceptación de su audiencia gracias a su canal de YouTube: EnchufeTv. El considera que los influencers existen desde tiempos remotos, y mucho antes del uso de redes sociales. Incluso grandes filósofos, políticos y cantantes han llegado a influir a las masas gracias su mensaje, letras o estilo musical. Una persona no escoge ser un influencer, sino que es el público el que lo escoge a uno. No debería ser visto como un fin sino como una consecuencia, cuando personas totalmente desconocidas, buscan seguir el estilo de vida de alguien más y se comienza a influir en ellos de cierta manera.

\section{Discusión}

A continuación, se presenta un diálogo entre los resultados presentados en la parte de hallazgos y la pregunta planteada al inicio de esta investigación. Se afirma que los influencers cuentan con gran aceptación del público, pero que no necesariamente lo determina el número de seguidores que posean. Para la maquillista Andrea Navarrete, la verdadera estrategia está en la cantidad de seguidores orgánicos que tengan y cuya decisión de compra se vea influenciada al momento de adquirir un producto. Así, la compra se aleja del modelo publicitario tradicional y se transforma en algo 100\% real.

Además, que la filosofía de la marca vaya acorde al perfil y al feed de cada influencer, como su estilo de vida, colores, patrones e imagen personal, respetando su propio nicho de mercado. Esto es de vital importancia para la influencer Karol Noboa, cuyo grupo objetivo es de principalmente jóvenes del género masculino, en edades entre 18 y 34 años de la ciudad de Quito, como se expone a continuación: 
Figura 1.
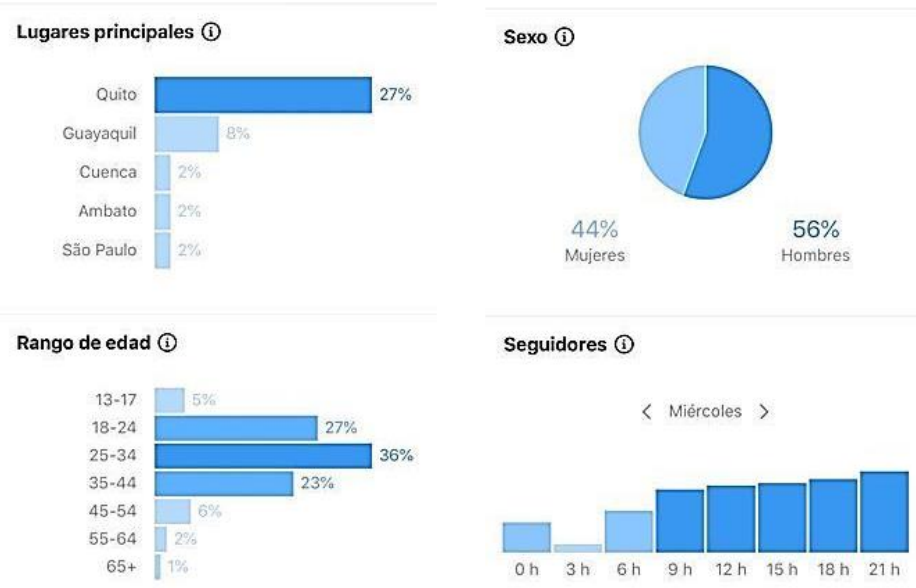

\section{Fuente: Cuenta personal de Karol Noboa en Instagram.}

Es notorio que no sólo marcas ecuatorianas pautan con influencers, sino que reconocidas marcas internacionales con operaciones en Ecuador apostaron por este modelo de negocio. Incluso, llegaron a utilizarlos como imagen de marca como es el caso de la actriz Erika Vélez y la marca de cosméticos Millani, o del guayaquileño Jesse Gallardo y la marca de ropa juvenil-deportiva Adidas, entre otros.

\section{Conclusiones}

Existe una comunidad consolidada de influencers en Ecuador y resulta cada vez más común que las empresas apuesten por el marketing digital para incrementar sus ventas en redes sociales. A diferencia de los medios tradicionales, el marketing de influencia es más novedoso y llega al consumidor de manera mucho más visual y efectiva. Pero que sobretodo, alcanza a su público objetivo de manera directa, al contrario del método tradicional (prensa, radio y televisión), donde la información llega a todos por igual.

La principal estrategia consiste en generar una comunidad de seguidores orgánicos que vayan de acuerdo a un nicho de mercado específico y que no importa que sea de un número reducido, siempre y cuando sean reales. Lo cual discrepa con la tendencia de muchos otros influencers, quienes piensan que mientras mayor sea el número de seguidores, mejor será el alcance de sus publicaciones y esto es totalmente falso.

En cuanto a la estrategia digital, los influencers la arman en base a publicaciones diarias, videos e historias. El cual consiste en un trabajo conjunto, donde la marca se alinea a la imagen y al estilo propio de cada influencer. Este último presenta un media kit o tabla de precios por publicación, adicional al producto que recibe por parte de la marca, llegando así a un acuerdo formal. Este modelo de negocio resulta muy conveniente para ambas partes, por lo que cada vez hay más personas interesadas en convertirse en influencers a modo de pasatiempo. 
En conclusión, el pautar con personas altamente influenciables resulta ser una alternativa rentable para las marcas, porque llega al grupo objetivo deseado. A diferencia de lanzar un comercial de televisión o pautar publicidad en una revista, los gerentes de marketing de las empresas decidieron aprovechar el talento joven, optimizando recursos económicos y humanos, para llegar a un segmento de la población cada vez más difícil de contactar, con el fin de ganar nuevos clientes y lo más importante, fidelizarlos a la marca.

\section{Bibliografía}

Angulo, S. (30 de Octubre de 2017). El 'influencer', un aliado de la publicidad para posicionar las marcas y productos de las empresas. Diario Expreso.

Bauman, Z. (2003). Amor líquido, acerca de la fragilidad de los vínculos humanos. España: Espa Ebook.

Bowman, S., \& Willis, C. (2003). Nosotros el medio. Cómo las audiencias están modelando el futuro de la noticias y la información. (J.D. Lasica ed.). (G. F. M., Trad.) Estados Unidos.

Brown, D. (2016). Evolución del marketing de influencers en los últimos años. Universidad de Sevilla, España.

Castagnino, A. (2017). Fashion Influencer Marketing. Moda digital a escala mundial. Universidad de Palermo, Argentina.

Cisneros, P. (3 de Julio de 2018). El Telégrafo. Obtenido de https://bit.ly/2SRYwcy

Curiel-Pérez, C., \& Luque, S. (2017). El marketing de influencia en moda. Estudio del nuevo modelo de consumo en Instagram de los millennials universitarios. adComunica. Revista de Estrategias, Tendencias e Innovación en Comunicación.

Curiel-Pérez, C., \& Sanz, P. (Enero de 2019). Estrategia de marca, Influencers y nuevos públicos en la comunicación de moda y lujo: Tendencia Gucci en Instagram. Revista Prisma Social(24).

Del Fresno, M. (2011). Netnografía. Investigación, análisis e intervención social online. Barcelona: UOC.

García, A. (2017). Publicidad nativa en instagram: el fenómeno de los influencers y la moda . Universitat Jaume, España.

Gómez, B. (2018). El influencer: herramienta clave en el contexto digital de la publicidad engañosa. Universidad Internacional de La Rioja.

Guerrero, E. (2017). Nuevas tendencias en el marketing de influencia: el caso de Instagram. Universidad Politécnica de Cartagena, Cartagena. 
INEC, I. E. (2018). Tecnologías de la Información y Comunicación. Encuesta Multipropósito - TIC 2018. Ecuador.

Jenkins, H. (2009). Fans, blogueros y videojuegos. La cultura de la colaboración. Barcelona, España: Paidós.

Jenkins, H. (2013). Cultura Transmedia. La creación de contenido y valor en una cultura en red. Barcelona, España: Gedisa.

Latour, B. (2008). Reensamblar lo social. Una introducción a la teoría del actor-red. Buenos Aires: Manantial.

Negroponte, N. (1995). El mundo digital (Primera edición ed.). Barcelona, España: Bailén.

Oscar López, C. B. (28 de Julio de 2018). Estrategias de Marketing Digital por medio de redes sociales en el contexto de las Pymes del Ecuador. Revista CienciAmérica.

Rubio, M. C. (2017). Marketing de Influencia en Instagram. Universidad de Sevilla, Sevilla, España. 